\title{
Successful vs. unsuccessful small group reflection: A narrative inquiry
}

\author{
Ping Zou*1, Arthy Visayanathan ${ }^{1}$, Christine Whyte ${ }^{1}$, Alla Pak ${ }^{1}$, Angela Cooper Brathwaite ${ }^{2}$, Qiongli Zhu ${ }^{3}$, Rick \\ Vanderlee 4 \\ ${ }^{1}$ School of Nursing, Nipissing University, Toronto, Ontario, Canada \\ ${ }^{2}$ Faculty of Health Sciences, University of Ontario Institute of Technology, Oshawa, Canada \\ ${ }^{3}$ College of Foreign Languages, Hainan University, Haikou, Hainan, China \\ ${ }^{4}$ Faculty of Applied and Professional Study, Nipissing University, Toronto, Ontario, Canada
}

Received: December 13, 2018

DOI: $10.5430 /$ jnep.v9n5p6
Accepted: December 26, 2018 Online Published: December 29, 2018

URL: https://doi.org/10.5430/jnep.v9n5p6

\begin{abstract}
There is a lack of research examining the factors which promote or hinder successful small group clinical practicum reflection seminars. The aim of this study was to explore key elements of successful small group reflection. Narrative inquiry was used as methodology. Three students consented to voluntarily participate in this study by learning on their experiences - both successful and unsuccessful - during their clinical reflection seminars. A 3-circle model was presented as a collective narrative. The Support Circle represents a safe and supportive environment where the reflection seminar is held. The Owner Circle represents the students' ownership in a reflection seminar. The Service Circle represents the educators' professional teaching services. To conclude, elements of a successful small group reflection included a safe leaning environment, a student-centered approach, and professional educator support. Within a safe learning environment, a successful small group reflection seminar should be owned by students and facilitated by a professional educator.
\end{abstract}

Key Words: Reflection, Narrative inquiry, Clinical practicum, Reflection seminar

\section{INTRODUCTION}

Reflective practice is a means of self-examination that includes looking back on previous experiences, analyzing them, and making an effort to improve future practice. ${ }^{[1]}$ Reflection, a learning approach which involves synthesis, validation, and appropriation of knowledge, attempts to synchronize our experience and reflection and aims to further our professional development and personal growth. Many countries have suggested the inclusion of reflection in nursing practice standards. ${ }^{[2]}$ Recently, reflection has been integrated into curricula classroom education, clinical practicum and other nursing education settings. ${ }^{[3-5]}$

Although there were some inconsistent findings, most studies acknowledged the potential benefits of reflection on nursing students' learning. As early as 2001, a qualitative study explored 14 graduate nursing students' experiences of reflection. The results suggested that most students found reflection in nursing education to have a positive effect. Students described themselves as being more aware, realistic, open, confident, and having an increased appreciation of the nursing profession. ${ }^{[6]}$ Another study examined eight nursing students' feelings towards reflective practice using an online

\footnotetext{
*Correspondence: Ping Zou; Email: pingz@nipissingu.ca; Address: School of Nursing, Nipissing University, 750 Dundas Street West, Toronto, Ontario, Canada.
} 
discussion and focus group interview. The findings showed that most students perceived reflection as a key component in nursing education, since reflection helped to develop their nursing skills and enhance their clinical competency. In this study, there was no consensus on whether or not reflection was a meaningful activity, but it was shown that the students learning style was pertinent to their perception of the usefulness of reflection. ${ }^{[7]}$ A qualitative study with 98 nursing students suggested that nursing students viewed reflection as a useful task which allows them to view the clinical situation from different angles, identify their personal learning style, improve their decision making, and develop responsibility and accountability in their practice. ${ }^{[8]}$ A recent study examined the concepts of reflection from both students' and teachers' perspectives using an interpretive ethnographic approach. Students reported that reflection helped to shift their thinking and actions, and also change and improve their practice. ${ }^{[9]}$

The Scholar Practitioner Program of Nipissing University is an innovative, accelerated Bachelor of Nursing program in Toronto, Canada. ${ }^{[10]}$ Instead of a traditional course-based design, every semester at the Scholar Practitioner Program is composed of 3-weeks of classroom inquiry, 9-weeks of clinical practicum, and 1-week of reflection. During the 9 weeks of clinical practicum, a group of around 10 students, will work with a faculty advisor in a 4-hour small group reflection seminar held weekly on campus. In the reflection seminars, the group discusses clinical experiences from the previous week. As some literature indicated, reflection is constantly practiced but its mechanism is not well understood. ${ }^{[3]}$ Often, the reflection seminars ran successfully. However, sometimes, students would consider them as time-wasting; the reasons behind this phenomenon are unknown. There is a lack of research examining the factors that promote or hinder successful small group reflection seminars. To explore what comprises an effective reflection, the following research questions were proposed: (a) What are the differences between successful and unsuccessful small group reflection seminars? (b) What are the key elements of a successful small group reflection seminar?

\section{MethodS}

Narrative inquiry was applied as the research methodology in this study. ${ }^{[11]}$ The assumption of narrative inquiry methodology is that human lives are shaped by past experiences. A narrative inquiry begins from a case in which people are involved and affected. It allows for reflection, which is a process to deepen the understanding of life events, leads to changes in professional practices, and facilitates learning and growth. ${ }^{[12]}$

Published by Sciedu Press
The study was conducted and sampled in an innovative undergraduate nursing program of a Canadian university. Research ethics approval was obtained from the university. Three students consented to participate in this study. They were female, from 22 to 25 years-old, with a previous non-nursing bachelor's degree, were second year students in a 2-year accelerated nursing program, and were full time students with annual incomes less than $\$ 20,000$. Three students were provided with a one-page reflection guide with a list of guiding questions. They were encouraged to write their reflections independently with the guiding questions to serve as a reference. Both the instructor and the students understood that reflections were voluntary and would not impact the student's current and future academic evaluations. To protect privacy and confidentiality, the names used in this paper were pseudonym rather than the real names of participants.

Participants' reflections were shared with the research team, common themes were drawn, and collective narrative was presented. Participants' narratives were coded, broken down into units of discrete thoughts, and classified under a content category. Additional categories were generated according to a process of constant comparison among participants' narratives. Each datum was compared with all others to assign its content category or identify a new category. Then, initial categories were reviewed systematically with the purpose of organizing them in a meaningful model. The researchers established trustworthiness and validity in the study through (a) acknowledgment of researcher biases and subjective judgments, (b) prolonged engagement with the data, (c) verification of data with the participants, and (d) reflexive bracketing. ${ }^{[13]}$ The principle investigator provided an option of debriefing and member check on the study's findings and three participants attended.

\section{ANNA'S NARRATIVES}

An experience that had truly tested my ability to self-reflect and communicate my sense of vulnerability was when I provided care for an elderly woman diagnosed with pneumonia. She had a behavioral safety alert noted on her chart as she has displayed physical aggression in times of frustration. I instinctively formed the assumption that this patient would be difficult to care for. I found myself proceeding with caution, wary of my words, maintaining distance, and completely guarded. I was nervous when performing her initial assessment, uncertain of whether she would accept or refuse my care. I managed to complete my assessment without difficulty. However, I was forced to self-reflect when I realized that I had allowed assumptions to hinder my thought process and provision of care. I reflected about the situation alone, wrote my thoughts on paper and read related jour- 
nals. ${ }^{[14]}$ During reflection class the following week, I shared my experience and concerns with my peers. I learned that many of my peers had similar encounters in their clinical practicum as well. As a group, we first reflected on our current practices and then discussed how we could create change in positive ways. We brainstormed and shared ideas of effective communication and therapeutic relationship with patients.

Once, the faculty advisor took the majority of the lead in conversations, leaving little to no room for students to use critical thinking skills and voice their opinions. The faculty advisor took an authoritative role, teaching students her own beliefs, practices, and what she considered to be important in nursing. This resulted in many of my peers being too afraid to speak out about their experiences. There was no freedom of speech within the group, and almost all the students were afraid of being judged or criticized for sharing their concerns. I didn't gain any new insight from this reflection group. The faculty advisor allowed no room for discussion, and the students didn't encourage each other to collaboratively come to conclusions, thus leaving many unanswered questions.

Group reflection allows for deeper analysis, critical thinking, and an opportunity to gain insight from collective experiences. ${ }^{[1,15]}$ When comparing both negative and positive reflective practices, a negative reflection event is like being left in a dark room with a lot of fear, while a positive reflection event is like participating in story time with a circle of close friends. The negative and positive reflection events differ in both the process and the outcomes, which influence one's willingness to share, learn, think, and improve practice.

\section{Chantel's narratives}

That was my first group reflection seminar in a new semester. Having had the same structure in previous semesters with different groups of learners, I knew it would take a week or two for the group to find our conversation style and to get comfortable with each other. A learner began the reflection by sharing an experience from her placement in a breastfeeding group for new mothers. The group, consisting of eight mothers and their babies was held at a local community centre. The student shared how she felt nervous as a student, but also as a young woman who was not a mother. She described what happened during her encounter, including details of what was felt, seen, heard, and how she interpreted what was happening. She reflected on her actions in that moment, which may have affected the care she was providing. The group had similar learning experiences, helped to analyze the situation, and identified the focus of learning. I offered compassion through active listening, body language, and the questions I asked. When I shared my reflection, I felt a sense of vulnerability as I opened up to the new group. This was my first community placement, but I found I could easily utilize learning from my previous placements. The group deepened their learning by linking experiences, questioning their perspectives, and recognizing similarities in others' reflections.

I made a medication error at a night shift during a previous hospital placement I miscalculated the time of the next dose by three hours. The hospital's computer system was not working properly. In the end, I administered the medication without verifying all of the correct information. After completing the appropriate paperwork and consulting with the physician, I reflected on the error with my faculty advisor. However, I never shared my mistake with my reflection group. I felt ashamed of my error and feared judgment and criticism. My fear inhibited me from gaining the support of my co-learners and prevented them from learning from me.

A positive outcome of reflection is the exploration of one's self. ${ }^{[5]}$ A learner examines bias, different perspectives, and how these things influence the care they provide. This exploration evokes emotions and a sense of vulnerability. What contributed to the positive experience of these reflection groups is the support from peers through shared experiences, allowing us to grow together. For me, a positive reflection event is like traveling with a close friend to a new place. You are able to explore the new city, try new things while always having someone you trust by your side. A negative reflection event is like traveling, but getting lost. It is overwhelming, confusing and sometimes very emotional. You feel scared, anxious, and unsure.

\section{AleXandra's narratives}

There were 12 students in my clinical reflection seminar. By the second session, we already had our class format planned out for the entire 9 weeks of reflection. The faculty advisor was supportive of everyone's learning, and made class engaging to all. We also agreed to focus each class on major nursing themes, giving us extra time to prepare in advance. To me, this worked great as I like to plan ahead. It helped me direct my attention to appropriate nursing themes one at a time, creating a systematic style of learning. I knew exactly which topic to prepare for each reflection, and that created meaning for each class. Because I knew exactly where I was in my studies and my schedule was predictable and organized, each reflection was meaningful, and helpful for me to monitor my academic progress.

In another reflection class, I just felt bad. There was a small reflection class (group of 4) with a "go-with-the-flow" style, meaning that it had no structure and no preparation by the 
faculty and learners. I found that we often spent time talking about things unrelated to school or practicums, which made me feel like the classes were a waste of time. The faculty encouraged us to lead the discussion, but she was not involved. This was frustrating for me as I like structure, but I also don't want to push others into my study routine. Most learners were too shy to initiate conversations and felt no pressure to do so without expectations, like in the previous class. Overall, I found no practical use in those reflection seminars. At the end of the semester, the faculty advisor suggested the last three weeks become independent study. I applauded this decision as the group didn't benefit from the seminars.

Having a smaller group encourages more inclusive participation and allows everyone's ideas to be heard. However, I realized that the faculty advisor plays a major role in facilitating and directing reflection seminars. Faculty members must guide dialogue, reflection, and critical thinking during classes. ${ }^{[16]}$ The disadvantages of the reflection event, thus, can be linked to faculty's discouraging, passive approach, despite their professional expertise. A positive reflection event is like having a good time with my family by a fireplace. A negative reflection event is like being in a room where everyone speaks different languages and we cannot understand each other. They differ in the way in which I would feel: comfortable and familiar in the positive, and unfamiliar and stressed in the negative event.

\section{Collective narratives: 3-Cicle MODEL}

Based on three student's narratives provided above, a 3-circle model was created to describe and interpret our collective narratives (see Figure 1). In this model, within a safe learning environment, a small group reflection seminar should be owned by students and facilitated by a professional educator.

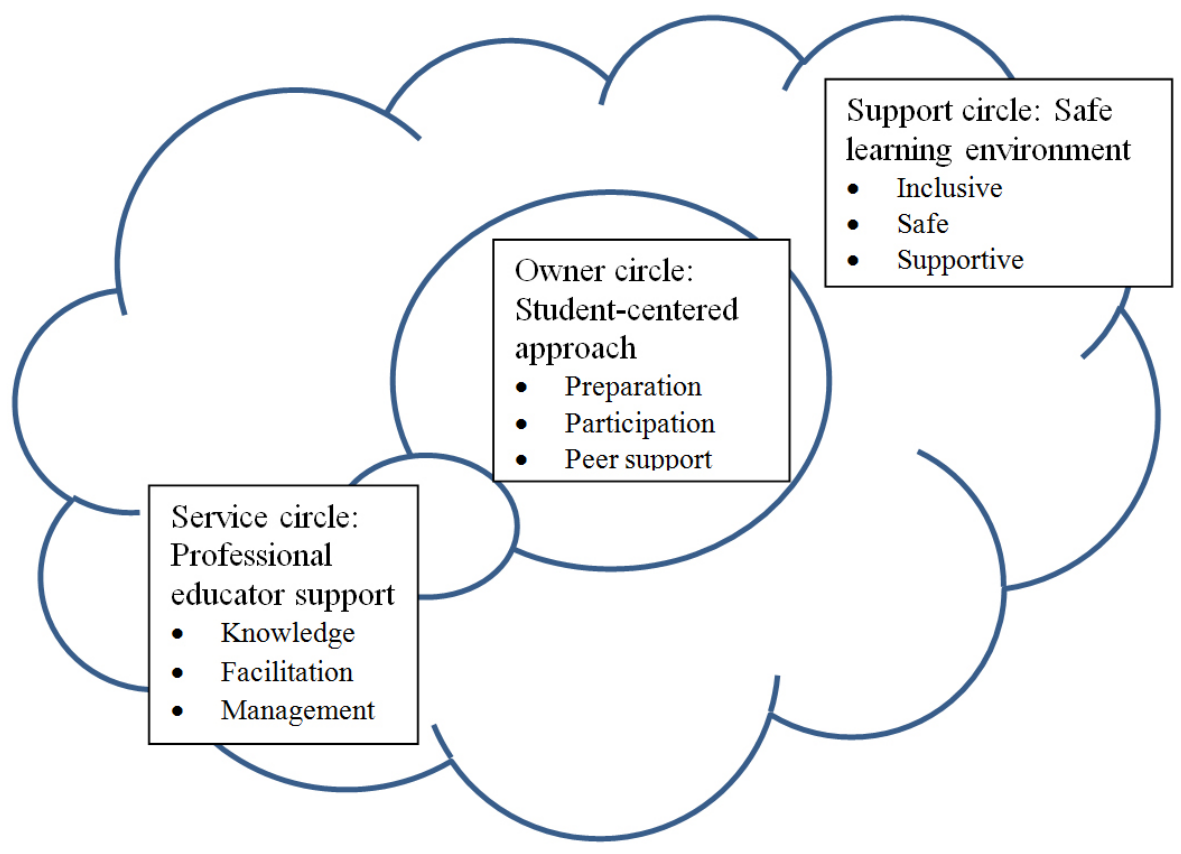

Figure 1. 3-circle model for a small group reflection seminar

In this model, the outer circle can be named the Support Circle, which represents the environment in which the reflection seminar is located. Reflection needs a safe and supportive environment, just like a student stated "a negative reflection event is like being left in a dark room with a lot of fear, while a positive reflection event is like participating in story time with a circle of close friends (Anna's narratives)." In addition, "a positive reflection event is like having a good time with my family by a fireplace (Alexandra's narratives)." The Support Circle should be as inclusive as possible, incorporat- ing faculty, department, school, and practicum settings. The better the support, and the safer the environment, the more meaningful and productive reflection will be.

The inner circle can be named the Owner Circle, which represents the student's ownership in a reflection seminar. The students are the only owners of the reflection and they should lead and benefit from it. The basic function of a reflection seminar is to have learners together to reflect on current practices and then discuss how to create change in positive ways (Anna, Chantel and Alexandra's narratives). Students 
in a group "deepened their learning by linking experiences, questioning their perspectives, and recognizing similarities in others' reflections (Chantel's narratives)". Participation is important. It would not be a meaningful reflection, if "most learners were too shy to initiate conversations and felt no pressure to do so without expectations (Alexandra's narratives)." Peer support is essential, since a reflection is just "like traveling with a close friend to a new place" and "you are able to explore the new city, try new things while always having someone you trust by your side (Chantel's narratives)".

The side circle, within the outer circle and partially overlapping with the inner circle, can be named the Service Circle. It represents the professional teaching service provided by educators. "Faculty members must guide dialogue, reflection, and critical thinking during classes (Alexandra's narratives).' Students appreciated well-organized reflection seminars, "because I knew exactly where I was in my studies and my schedule was predictable and organized, each reflection was meaningful, and helpful for me to monitor my academic progress (Alexandra's narratives)." Students did not favor "faculty's discouraging, passive approach" (Alexandra's narratives), and that the faculty "took the majority of the lead in conversations, leaving little to no room for students to use critical thinking skills and voice their opinions (Anna's narratives)." That would be a failed reflection, if "there was no freedom of speech within the group, and almost all the students were afraid of being judged or criticized for sharing their concerns (Anna's narratives)." The educators should be professionally trained, knowledgeable and able to provide guidance while avoiding dominance.

\section{Discussion}

Safe learning environment. A safe learning environment is the foundation of a successful small group reflection, as reflection exposes private thoughts to the public sphere for assessment, judgment, and classification. ${ }^{[17]}$ Reflective practice is based on the assumption that one is willing and able to reflect. ${ }^{[9,18]}$ Findings of our current study suggested that an open, honest, and trusting learning environment opens up the conversation and leads to successful reflection; on the other hand, an unsure, non-supportive, dictated environment shuts down conversation and causes the failure of the reflection. These findings are consistent with other research. A qualitative study in a part-time post-registration nursing diploma program suggested that reflective learning may not necessarily be an enjoyable experience as the current nursing culture imposes barrier to reflecting and learning from experience. ${ }^{[19]}$ These barriers affect the willingness of learners to become vulnerable and take responsibility for their own learning. Another study indicated that reflection classes were enhanced when students were not graded for their reports of clinical learning, and when problematic cases were encouraged to be discussed as a group. ${ }^{[20]}$

A safe learning environment should be able to contain and transform the students' emotional stress and difficulties in the clinical practicum to empower learning experiences. Nurses often discuss patients' feelings, but assume that their own emotions are irrelevant. ${ }^{[14]}$ Nursing students frequently absorb patients' emotions and do not know how to respond to distressing emotional challenges. ${ }^{[21]}$ Negative feelings and unexpressed emotions could be accumulated and impact students' morale and learning ability in clinical practice. A safe learning environment in a small group reflection provides a healthy outlet, allowing students to express emotions, share feelings, and further develop emotional intelligence. ${ }^{[21,22]}$ Through learning to express their own emotions and relate to clients' emotions, reflection can also empower students to better their patient-centered care, thus increasing job satisfaction. ${ }^{[8]}$ Reconstructing experiences through reflection offers the opportunity to see how one's emotions come into play from a new perspective, which may result in a change of behavior in the future. ${ }^{[23]}$

Student-centred approach. While students are owners of their reflection sections, they should be well-prepared for the reflective process. Reflection is an active and complicated process including examining a situation from different perspectives, seeking various explanations, and striving for better outcomes. ${ }^{[5]}$ Before the reflective section, students need to self-reflect and prepare to present their clinical stories to peers. A review of literature might be needed to facilitate understanding clinical stories using existing evidence. Students should understand that, when the group members examine clinical stories, different perspectives may surface. Thus, students should be open to different perspectives, various explanations, and new information.

Findings of our current study indicated the importance of peer support in a small group reflection. Evidence also suggested that peer support is a common strategy for students to cope with anxiety, particularly in the early stages of clinical practice. ${ }^{[24]}$ Because they hold similar social status and share similar experiences, peers can hold similar viewpoints, better understand each other's vulnerability and emotional stress, and be able to provide greater sympathy and more feasible recommendations. Through reflecting on personal and peer experiences, students can support one another, evaluate each other's performance during nursing practice, and work together to make sense of what happened and how it could be improved in the future. ${ }^{[25]}$ 
Students need to be aware of their personal learning styles and prepare to effectively use various learning strategies to reach desired outcomes. Both individual and team approaches will be used in different learning activities, which may not always fit everyone's needs. The use of an individual kinesthetic learning strategy might be effective in engaging learners and improving learning outcomes, ${ }^{[26]}$ while teambased learning might help in building skills, concept analysis, critical thinking, and problem solving. ${ }^{[27]}$ An activity such as a learning style self-quiz can be used to distinguish individuals into kinesthetic, visual, and auditory learners, helping students to understand themselves and effectively use various teaching resources. ${ }^{[28]}$ While the faculty strives to design learning activities to fit with an individual's learning styles, students should take time to explore the learning routines and know strategies to learn in various learning settings.

Professional educator support. An educator is a facilitator and a supportive participant in a small group reflection. With adequate training and a solid understanding of the use of reflection, an educator can supervise reflection sessions for nursing students. Utilizing appropriate teaching strategies, the educator will encourage students to become aware of the knowledge, beliefs, and values that guide their practice. As a facilitator, the educator should aim to challenge students to identify disconnects between their beliefs and clinical practice. Once the problem has been identified, faculty should guide students to set up their professional goals and take action to make change. ${ }^{[4]}$ Awareness of an experience and being able to describe it may be difficult. However, when facilitated by a trained educator who provides valuable insight and structure to the process of reflection, students will develop the ability to articulate clinical issues. ${ }^{[15]}$ There are several strategies to promote reflection, including art, mythic journey scenarios, storytelling, group debriefing, and journal writing. A study examining the educational outcomes of reflective learning found that it was equally effective as conventional teaching in classroom settings; however, students demonstrated an enhancement in overall learning when reflective teaching strategies were utilized by the faculty. ${ }^{[1]}$

Findings of our current study suggested that students benefited from a well-structured reflection which effectively uses time to have a meaningful discussion related to their practice. This preference might be related to the characteristics of adult education, which is relevancy oriented, time-sensitive, and aimed at practical use of information. ${ }^{[29]}$ Existing evidence also revealed that having a structure for reflection aids in finding meaning in the reflection and maintaining it as a daily practice. ${ }^{[18,30]}$ For example, the use of guided questions in reflection classes will allow students to view various situations from different perspectives, consequentially gaining new knowledge from their clinical incidents. ${ }^{[30]}$ In addition, Henderson's 5-R's of reflection scale, which differentiates five levels of reflection, including reporting, responding, relating, reasoning, and reconstruction, can be used as a framework to promote continuous reflection. ${ }^{[31]}$ From the reporting level where students only describe the event, to the reconstruction level where students are able to use abstract thinking to generalize and apply learning, each level progresses in complexity, making reflection events more meaningful. A qualitative study suggested that use of structured classroom reflection improved the development of perceived clinical judgment and clinical confidence in Bachelor of Science nursing students. ${ }^{[4]}$

Unbalanced power between students and the faculty might be barriers to reflection. Findings of our current study indicated that students were not favorable to reflection sections which are dictated by their professors. Existing literature presented consistent findings. Power is omnipresent in an adult classroom, the flow of power can be redirected, but can never be denied or erased. ${ }^{[32]}$ In the reflection events, faculty need to be aware of potential power issues and redirect power in order to benefit student learning. Since learning is a social interaction among individuals, it is likely that the values and opinions of students and faculty differ. Reflection should be open, involving genuine thought, discussing both positive and negative feelings, and be derived from personal and professional integrity. ${ }^{[1]}$ Educators need to understand that the excessive use of power will be a barrier to effective learning. They also need to recognize that they are always learning from their students.

Implications. The nursing academic and practice community as a whole, including schools, practice organizations, and professional associations, should further promote reflective practice as a part of nursing professionalism. A safe environment is a positive component of reflective practice. Thus, educators and students should work together to create and protect a safe learning environment for themselves.

Students should assume ownership of the reflective learning and be well prepared for a meaningful reflective process. In addition, educational facilitators should encourage student leadership and peer support during reflective discussions. These strategies would empower students, enhance their growth and development, and better prepare them for future practice.

Nurse educators should assume the responsibilities of promoting reflective teaching and learning. First, educators should be trained in the values and knowledge of reflective practice and encouraged to improve their facilitation skills. ${ }^{[3]}$ Second, educators should strive to apply innovative pedagogy 
to promote effective reflection and meet students' learning needs. Third, educators should be effective partners in a reflective event and collaboratively work with students to achieve learning goals. ${ }^{[33]}$ Imbalance of power should be prevented and reciprocal learning promoted. Finally, educators should strive to continuously reflect on their teaching and improve in both nursing knowledge and facilitation skills. ${ }^{[1]}$

The strengths of our current study include using narrative inquiry, which promotes deep understanding and learning from real human experiences. Moreover, this study focused on student perspectives, which is significant in current studentcentred pedagogy. The limitations of our current study are a small sample size and conducting the study in one educational setting. Thus, generalizability of the study is limited. Future research should continue using narrative inquiry and other methodologies to explore student experiences of reflective learning and its impact on their practice in various settings among different student populations. In addition, the examination of the educator's experiences of reflective teaching should be emphasized due to lack of existing evidence.
Future studies might need to address the issues raised in our current study, such as safe learning environment, power issues, different learning styles, and pedagogies in reflection teaching and learning. Finally, expanding the use of quantitative approaches might test the 3 -circle model and the outcomes of reflective teaching and learning.

\section{Conclusion}

Using narrative inquiry as a research methodology, our current study suggested three important elements in a small group reflective seminar, which are safe learning environment, student-centred approach, and professional educator support. Based on individual student narratives, a 3-circle model was proposed as a collective narrative to illustrate the characteristics of a successful reflection event. Future studies should continue to explore experiences of both students and educators, and use various research methodologies to examine the outcomes of reflective teaching and learning.

\section{CONFlicts OF INTEREST Disclosure}

The authors declare that there is no conflict of interest.

\section{REFERENCES}

[1] Ruth-Sahd LA. Reflective practice: a critical analysis of data-based studies and implications for nursing education. J Nurs Educ. 2003; 42(11): 488-97. PMid:14626387

[2] Burton AJ. Reflection: nursing's practice and education panacea? J Adv Nurs. 2000; 31(5): 1009-17. https ://doi.org/10.1046/j. $1365-2648.2000 .01395 . x$

[3] Braine ME. Exploring new nurse teachers' perception and understanding of reflection: an exploratory study. Nurse Educ Pract. 2009; 9(4): 262-70. PMid:18842461 https://doi.org/10.1016/j.ne pr.2008.08.008

[4] Glynn DM. Clinical judgment development using structured classroom reflective practice: a qualitative study. J Nurs Educ. 2012; 51(3): 134-9. PMid:22283156 https://doi.org/10.3928/0148 4834-20120127-06

[5] Jacobs S. Reflective learning, reflective practice. Nursing. 2016; 46(5): 62-4. PMid:27096919 https://doi.org/10.1097/01.N URSE. 0000482278.79660.f2

[6] Glaze JE. Reflection as a transforming process: student advanced nurse practitioners' experiences of developing reflective skills as part of an MSc programme. J Adv Nurs. 2001; 34(5): 639-47. https://doi.org/10.1046/j.1365-2648.2001.01793.x

[7] Smith A, Jack K. Reflective practice: a meaningful task for students. Nurs Stand. 2005; 19(26): 33-7. https://doi.org/10.7748/ns $.19 .26 .33 . \mathrm{s} 61$

[8] Chong MC. Is reflective practice a useful task for student nurses? Asian Nurs Res (Korean Soc Nurs Sci). 2009; 3(3): 111-20. https : //doi.org/10.1016/S1976-1317(09)60022-0

[9] Bulman C, Lathlean J, Gobbi M. The concept of reflection in nursing: qualitative findings on student and teacher perspectives.
Nurse Educ Today. 2012; 32(5): e8-13. PMid:22071273 https: //doi.org/10.1016/j.nedt.2011.10.007

[10] Zou P, et al. Strength-based Student-led Presentations in Clinical Reflection Seminars: Narratives of Learning Experiences. Journal of Nursing Education and Practice. 2018; 8(3): 48-55. https : //doi.org/10.5430/jnep.v8n3p48

[11] Clandinin DJ. Handbook of Narrative Inquiry: Mapping a Methodology. Thousand Oaks: CA: Sage; 2007.

[12] Connelly FM, Clandinin DJ. Narrative Inquiry, in Handbook of Complementary Methods in Education Research, G. Green, et al., Editors. Lawrence Erlbaum Associates: Washington, DC. 2006.

[13] Ahern KJ. Ten tips for reflexive bracketing. Qualitative Health Research. 1999; 9(3): 407-411. https://doi.org/10.1177/1049 73239900900309

[14] Schutz S. Reflection and reflective practice. Community Pract. 2007; 80(9): 26-9.

[15] Bertero C. Reflection in and on nursing practices - how nurses reflect and develop knowledge and skills during their nursing practice. International Journal of Caring Sciences. 2010; 3(3): 85-90.

[16] Schwind JK, et al. Fostering person-centered care among nursing students: creative pedagogical approaches to developing personal knowing. J Nurs Educ. 2014; 53(6): 343-7. PMid:24855990 https://doi.org/10.3928/01484834-20140520-01

[17] Cotton AH. Private thoughts in public spheres: issues in reflection and reflective practices in nursing. J Adv Nurs. 2001; 36(4): 512-9. https://doi.org/10.1046/j.1365-2648.2001.02003.x

[18] Caldwell L, Grobbel CC. The importance of reflective practice in nursing. International Journal of Caring Sciences. 2013; 6(3): 319326

[19] Platzer H, Blake D, Ashford D. Barriers to learning from reflection: a study of the use of groupwork with post-registration nurses. J Adv 
Nurs. 2000; 31(5): 1001-8. https ://doi.org/10.1046/j.1365 $-2648.2000 .01396 . x$

[20] Klimczak ML. Reflective journal writing: Nursing students' perspectives. ProQuest Dissertations Publishing. 2002.

[21] Rees KL. The role of reflective practices in enabling final year nursing students to respond to the distressing emotional challenges of nursing work. Nurse Educ Pract. 2013; 13(1): 48-52. PMid:22854313 https://doi.org/10.1016/j.nepr.2012.07.003

[22] Donovan MO. Implementing reflection: insights from pre-registration mental health students. Nurse Educ Today. 2007; 27(6): 610-6. PMid:17081658 https://doi.org/10.1016/j.nedt.2006.09 .001

[23] Johnson JA. Reflective learning, reflective practice, and metacognition: the importance in nursing education. J Nurses Prof Dev. 2013; 29(1): 46-8. PMid:23486157 https://doi.org/10.1097/NND. Ob013e31827e2f 27

[24] Hamrin V, et al. Evaluation of peer-led support groups for graduate nursing students. J Nurs Educ. 2006; 45(1): 39-43.

[25] Mariani B, Cantrell MA, Meakim C. Nurse educators' perceptions about structured debriefing in clinical simulation. Nurs Educ Perspect. 2014; 35(5): 330-1. https://doi.org/10.5480/13-1190.1

[26] Wagner EA. Using a kinesthetic learning strategy to engage nursing student thinking, enhance retention, and improve critical thinking. J Nurs Educ. 2014; 53(6): 348-51. PMid:24814353 https: //doi.org/10.3928/01484834-20140512-02
[27] Hickman SE, Wocial LD. Team-based learning and ethics education in nursing. J Nurs Educ. 2013; 52(12): 696-700. PMid:24304259 https://doi .org/10.3928/01484834-20131121-01

[28] Wieland PS, et al. Examining the impact of modality and learning style preferences on recall of psychiatric nursing and pharmacology terms. Nurse Educ Today. 2018; 66: 130-134. PMid:29702442 https://doi.org/10.1016/j.nedt.2018.04.003

[29] Crookes K, Crookes PA, Walsh K. Meaningful and engaging teaching techniques for student nurses: a literature review. Nurse Educ Pract. 2013; 13(4): 239-43. PMid:23683818 https://doi.org/10.101 6/j.nepr.2013.04.008

[30] Ashby C. The benefits of reflective practice. The Journal for Nurses in General Practice. 2006; 32(9): 35-37.

[31] Henderson K, Napan K, Monteiro S. Encouraging reflective learning: An online challenge, in Beyond the comfort zone: Proceedings of the 21st ASCILITE Conference (pp. 357-364). Perth, 5-8 December., C.M. R. Atkinson, D. Jonas-Dwyer \& R. Phillips (Eds), Editor. 2004.

[32] Brookfield SD. The concept of critically reflective practice, in Handbook of adult and continuing education, W.A. L. and E.R. Hayes, Editors. Jossey-Bass: San Francisco. 2000.

[33] Epp S. The value of reflective journaling in undergraduate nursing education: a literature review. Int J Nurs Stud. 2008; 45(9): 1379-88 PMid:18325522 https://doi.org/10.1016/j.ijnurstu. 200 8.01 .006 